\title{
Channel Quality Driven Discontinuous Reception (DRX) Model for Power Saving in LTE System
}

\author{
Md. Imran Hossain ${ }^{1}$ and Mahmud Matin ${ }^{1}$ \\ ${ }^{1}$ Comilla University
}

May 5, 2020

\begin{abstract}
Long-Term Evolution (LTE), which is a standard for wireless communication, has incorporated Discontinuous Reception (DRX), a power-saving strategy having the primary purpose of enhancing energy-saving at the user equipment (UE). Nevertheless, for the networks that have varying channel quality, it is not possible all the time for fixed DRX parameters to obtain the desired improvement. This research introduces a new model based on CQI (Channel Quality Indicator) that will reduce energy consumption by eliminating unnecessary wakeups of UE's and also achieve reduced latency. As the DRX mechanism saves UE's energy usually by increasing latency, a tradeoff is necessary between these two performance factors. LTE networks can optimize DRX model parameters for minimizing power consumption based on CQI reporting by UEs and MCS (Modulation and Coding Scheme) assignments by eNodeB as network channel quality is not equal. In this research, an adaptive DRX model is developed, namely CQI DRX, that maintains a balance between power saving and latency. The simulation process is carried out using ns3, a discrete event network simulator. This research shows that energy consumption can be decreased by approximately $13 \%$, and latency can be diminished by around $7 \%$ compared with static DRX.
\end{abstract}

\section{Hosted file}

MainENGR.pdf available at https://authorea.com/users/295026/articles/423597-channel-qualitydriven-discontinuous-reception-drx-model-for-power-saving-in-lte-system
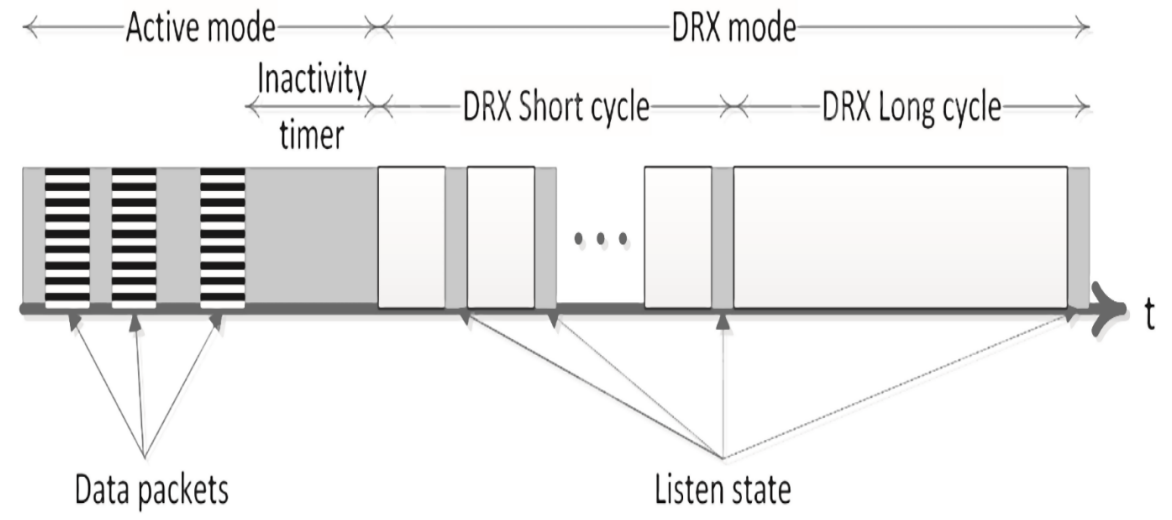

$\square$ Active state $\quad \square$ Sleep state 

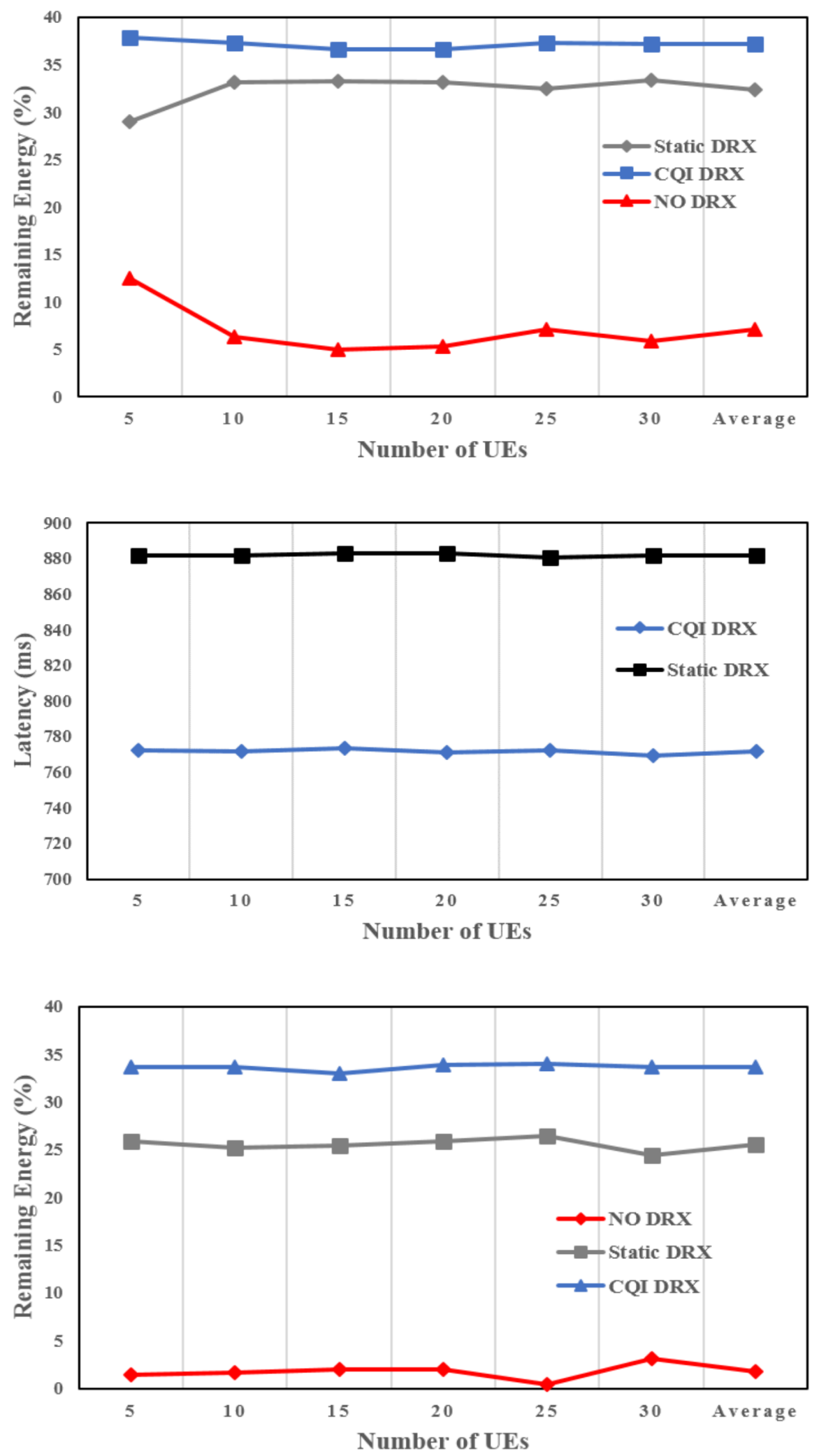

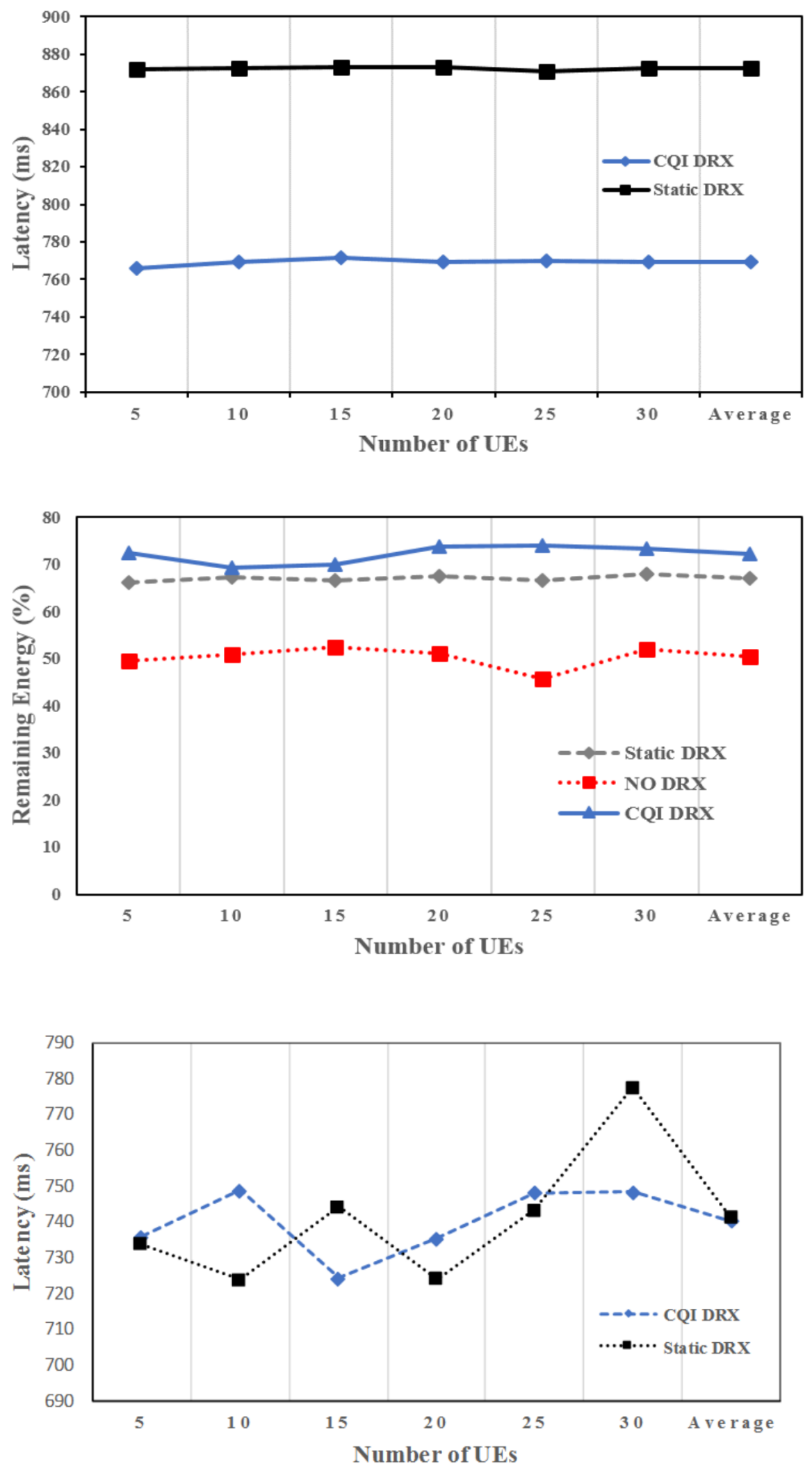

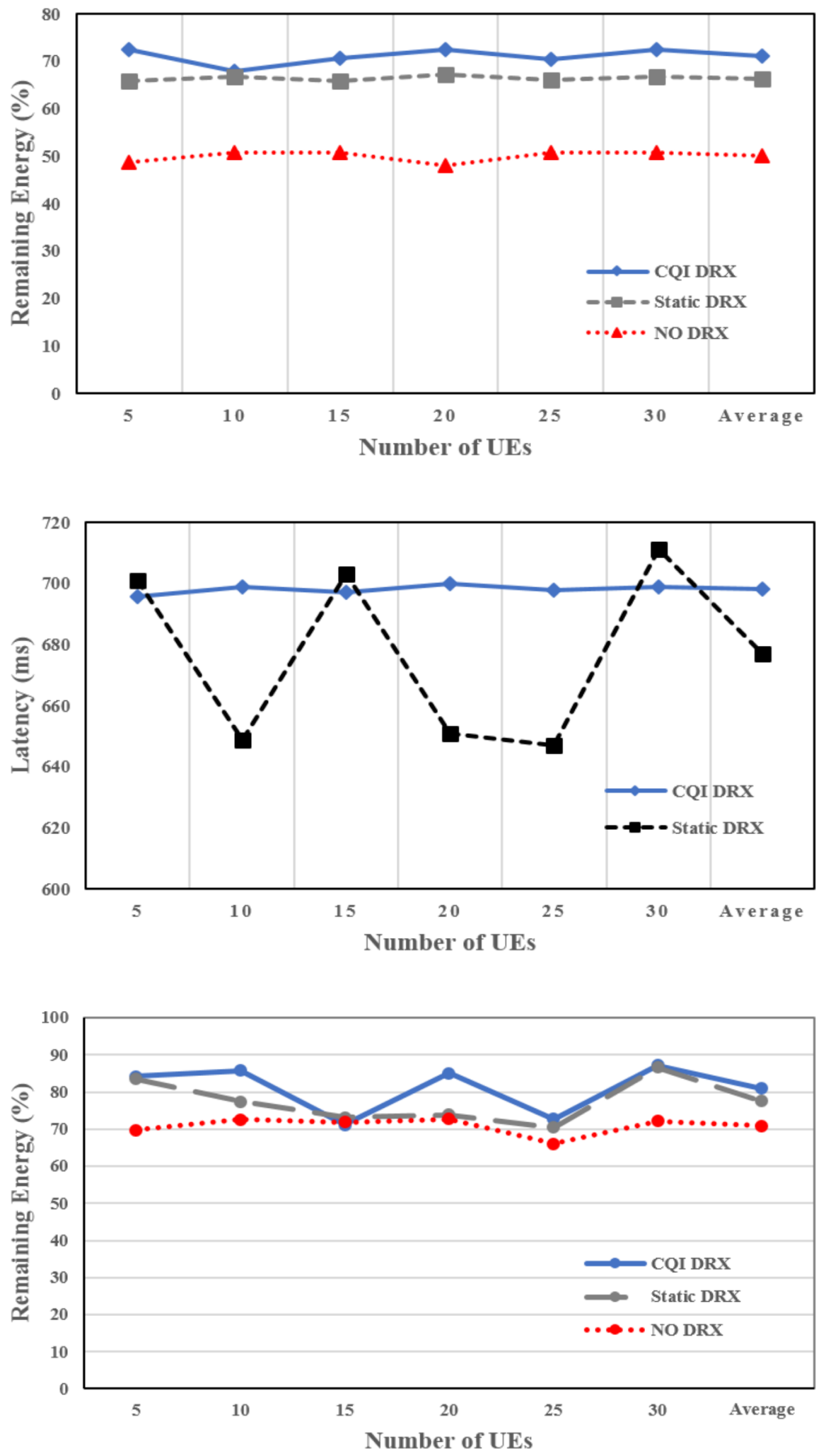

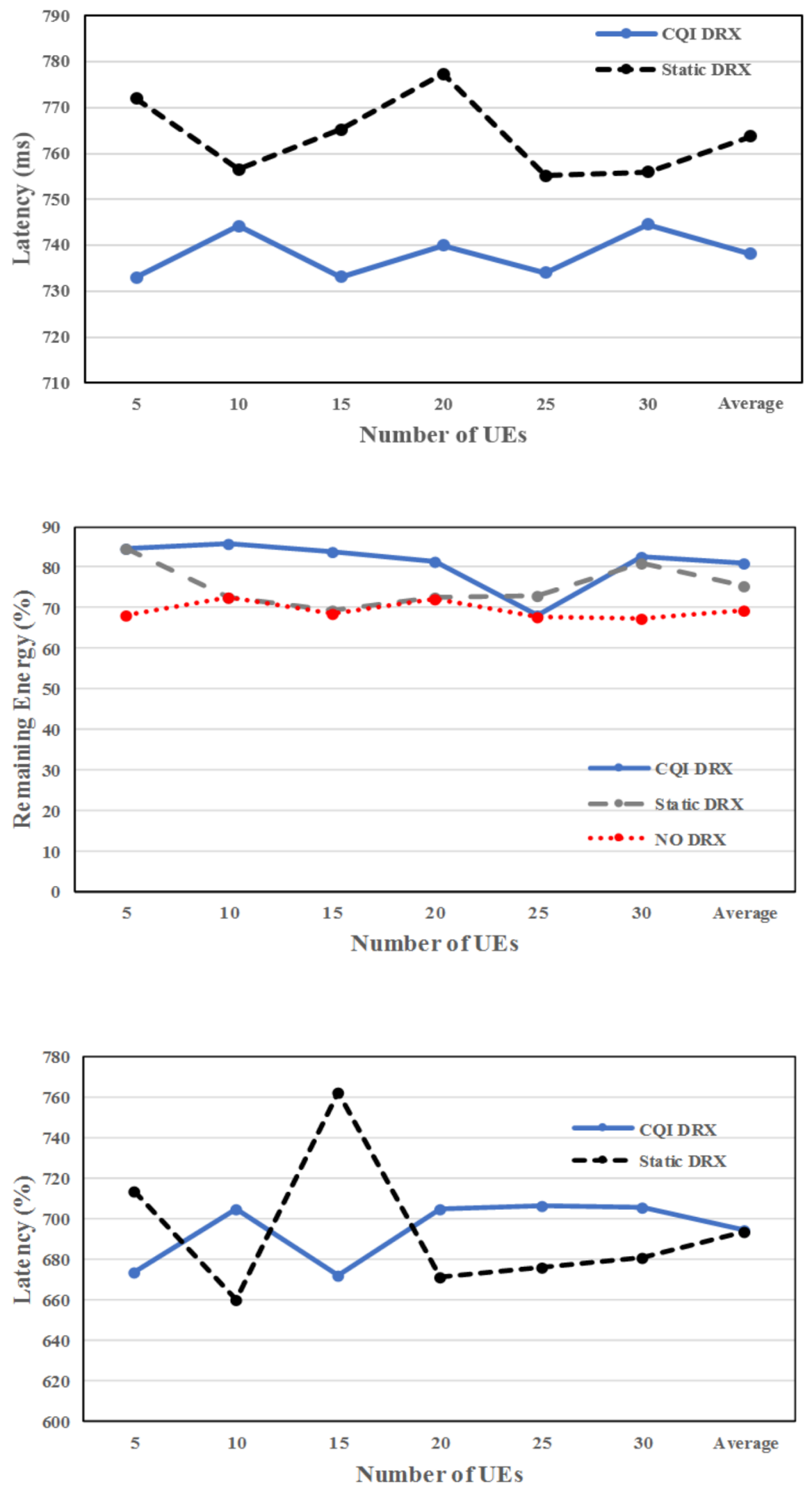

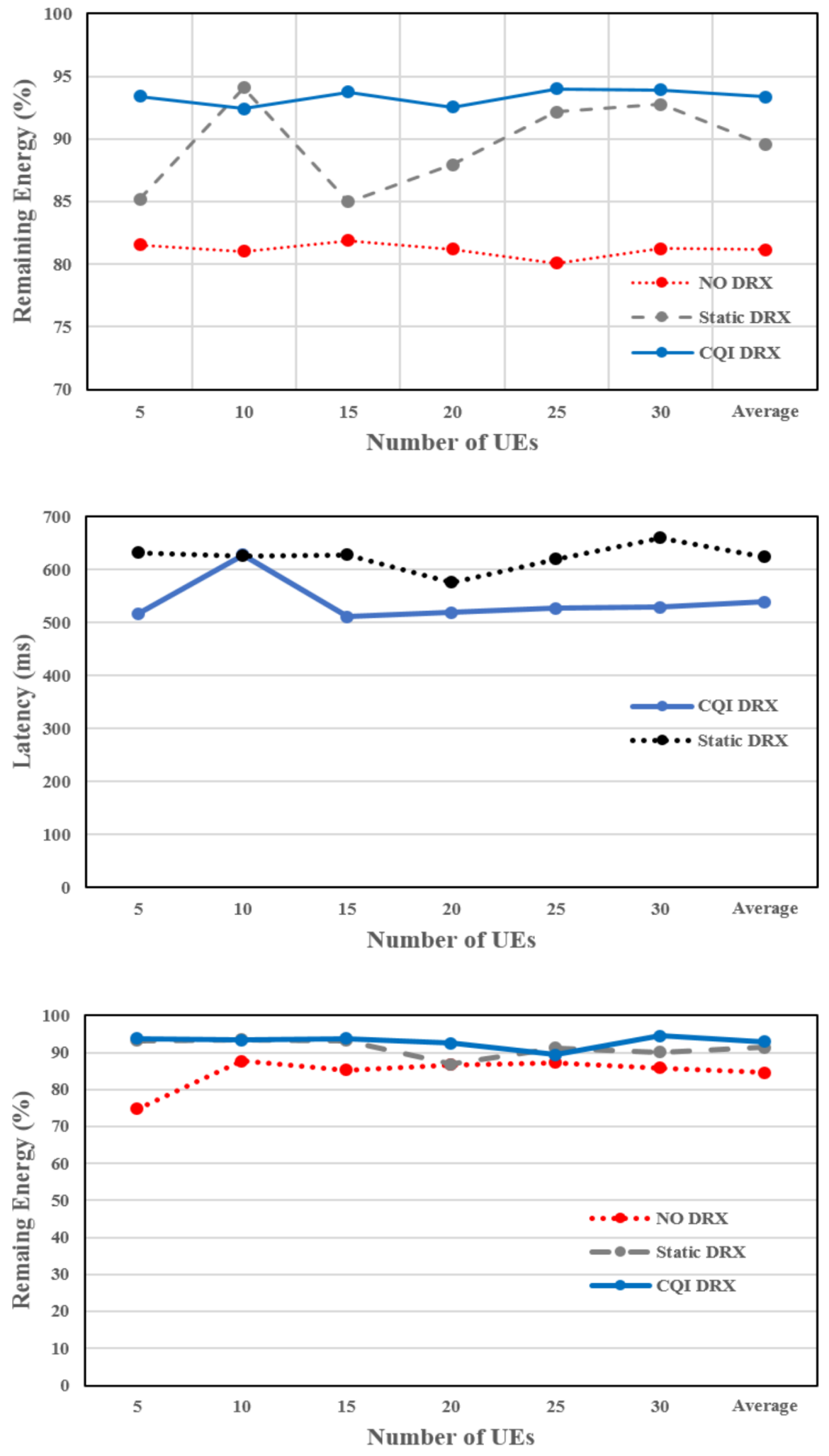

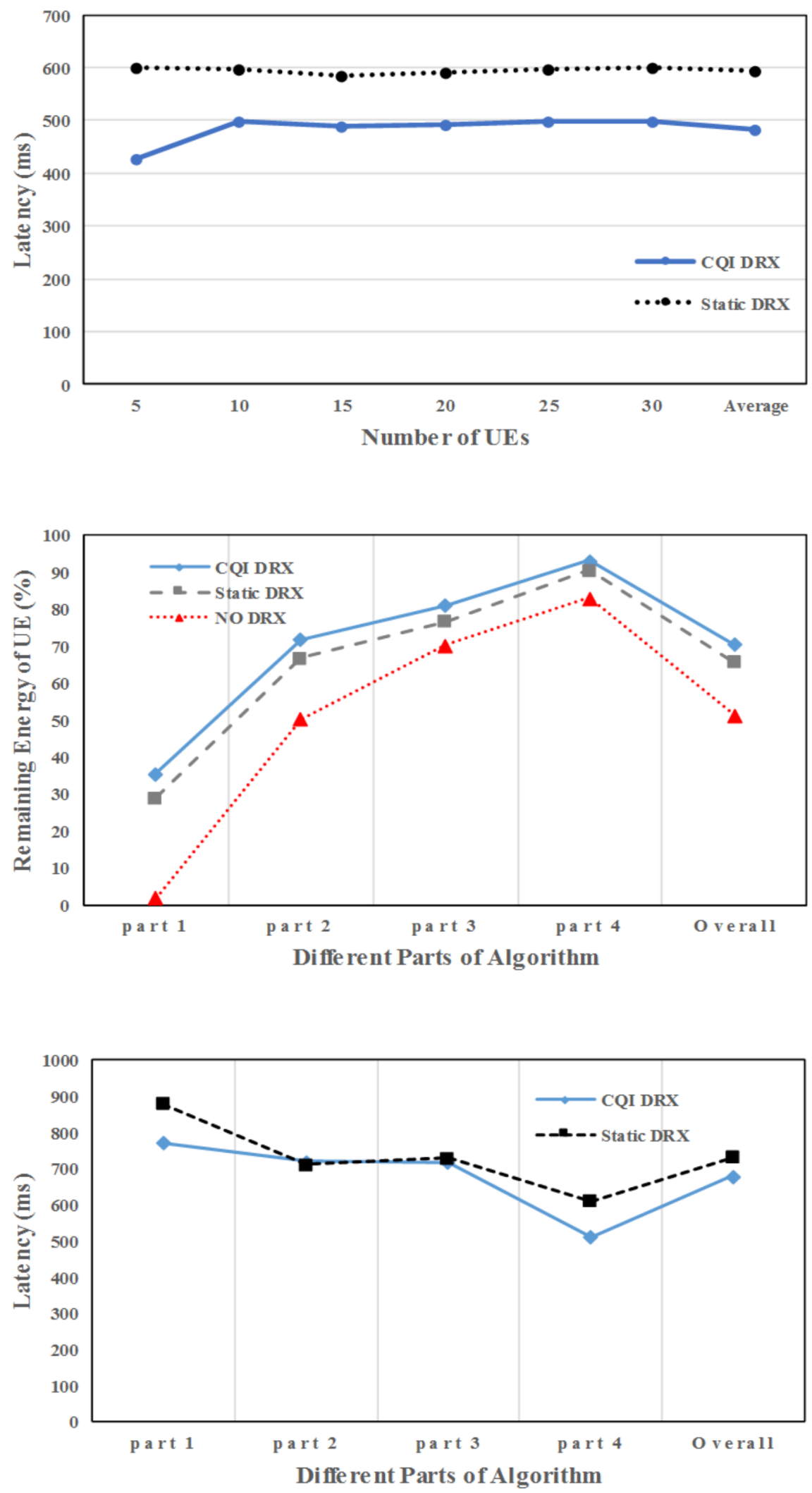

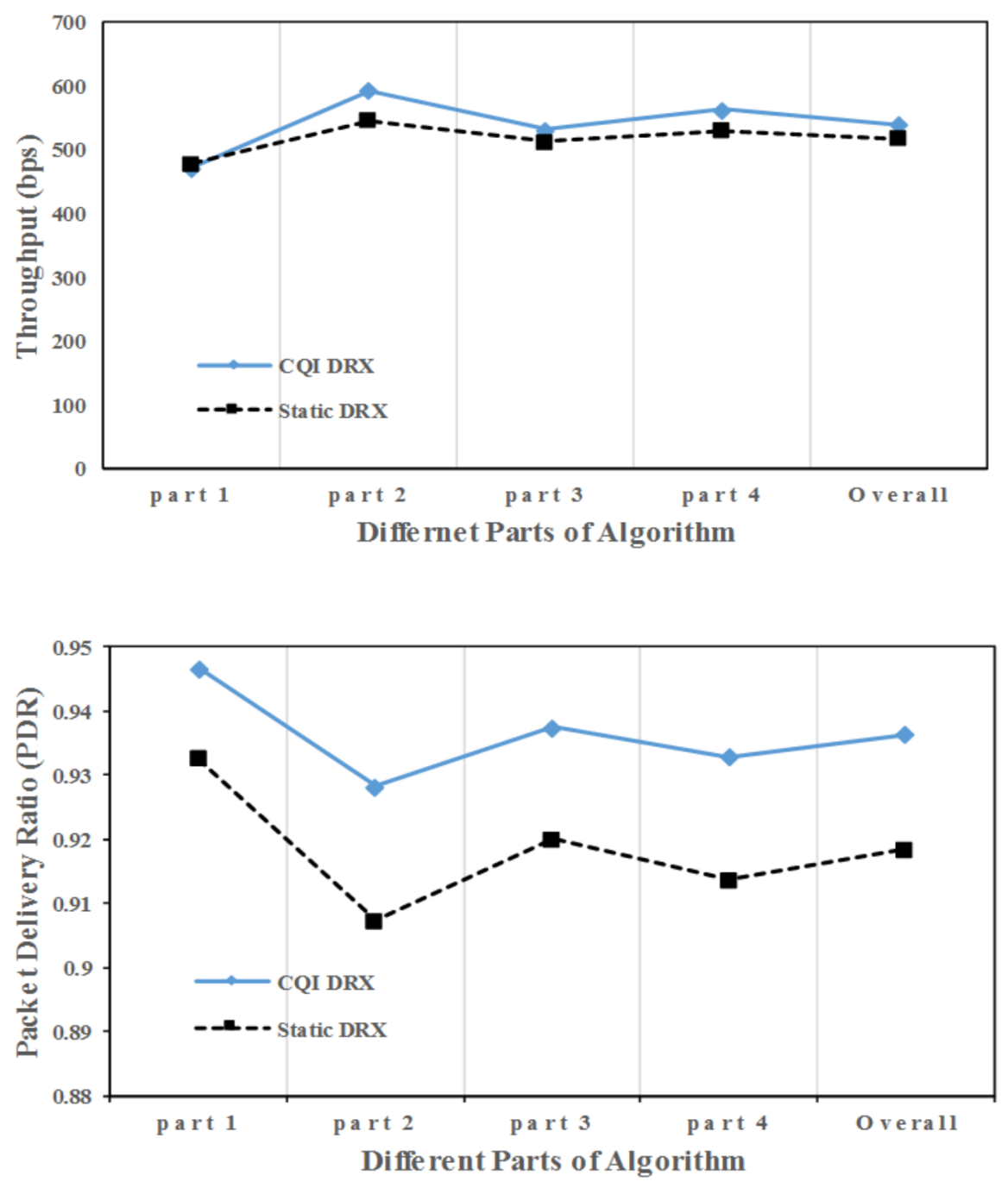